\title{
STRATEGI PENGEMBANGAN USAHA SUSU KUDA SUMBAWA DI KECAMATAN LENANGGUAR DAN MOYO UTARA KABUPATEN SUMBAWA NUSA TENGGARA BARAT
}

\author{
Samuyus Nealma ${ }^{1)}$, Sri Hidanah ${ }^{2)}$, Nenny Harijani ${ }^{3)}$, \\ 1) Student ${ }^{2)}$ Department of Animal Husbandry ${ }^{3}$ Departement of Veterinary Public Health Faculty of \\ Veterinary Medicine Airlangga University
}

\begin{abstract}
This study aims to analyze the factors strengths, weaknesses, opportunities and threats, as well as determining the strategic priorities that must be done in the development of Sumbawa horse milk in the district Lenanggguar and North Moyo Sumbawa of West Nusa Tenggara. The sampling technique is a technique Snowball Sampling by tracing where the respondent by asking a few people who are considered as key informants at the sites. Data collection techniques in this study is observational techniques, questionnaires, interviews and documentation. The analysis used in this development strategy include analysis matrix IFE (Internal Factor Evaluation) and EFE (External Factor Evaluation), a SWOT analysis, and analysis QSPM. The results of the study indicate that the main strength factor is the cheaper of price with the score 0.399. The main drawback is unlabeled BPOM with a score of 0.234 . The main opportunities that can be utilized by businesses Sumbawa horse milk is a healthy and natural living trend as well as the benefits and efficacy of credits that have been known to the public with the same score of 0.344 . The main threat is found at the level of inflation with a score of 0.272 . Based on these results main strategy for Sumbawa horse milk business depelopment was improve the marketing strategy in a concentrated.
\end{abstract}

\section{PENDAHULUAN}

Secara nasional populasi kuda terus mengalami penurunan, tidak terkecuali di kabupaten Sumbawa yang menjadi sentral peternakan. Berdasarkan laporan Dinas Peternakan Kabupaten Sumbawa (2014) jumlah kuda Sumbawa 2 tahun terakhir mengalami penurunan mencapai 7,7\%. Penurunan ini salah satunya disebabkan oleh kegunaan kuda di masyarakat yang telah tergantikan.

Di kabupaten Sumbawa kuda tidak hanya dimanfaatkan sebagai alat transportasi atau alat angkut hasil pertanian, tetapi dimanfaatkan pula sebagai penghasil susu yang kemudian dikenal sebagai susu kuda Sumbawa.

Susu kuda Sumbawa (SKS) memiliki daya antimikroba yang mampu menghambat pertumbuhan 9 jenis bakteri patogen dan perusak pangan yakni Shigella bodyii, Salmonella typhymurium, Staphyloccus aureus, Vibrio cholera, Bacillus cereus, Pseudomonas aeruginosa, Echeria coli, Bacillus subtillus, Mikrococcus leteus (Hermawati dkk, 2004). Susu kuda juga memiliki kandungan vitamin C lebih tinggi daripada susu sapi yakni $147 \mathrm{mg} / \mathrm{L}$ dibandingkan $0,98 \mathrm{mg} / \mathrm{L}$ pada susu sapi (Salimei dan Fantuz, 2012). Tingkat kecernaan susu kuda lebih baik daripada susu yang berasal dari ternak lainnya, ini ditunjukkan dengan kandungan asam lemak rantai panjang, nitrogen dan kolesterol yang rendah (Sheng dan Fang, 2009).

Namun potensi usaha susu kuda Sumbawa nampaknya belum disadari sepenuhnya baik oleh masyarakat maupun pemerintah terkait.

Terdapat 2 kecamatan yang selama ini dikenal sebagai penghasil susu kuda Sumbawa yakni kecamatan Lenangguar dan Moyo Utara. Berdasarkan hal itu maka diperlukan strategi pengembangan usaha susu kuda Sumbawa di kecamatan Lenangguar dan Moyo Utara kabupaten Sumbawa Nusa Tenggara Barat.

\section{METODE PENELITIAN}

Penelitian dilakukan secara survey berdasarkan pada metode deskripsi analisis, yaitu mengambarkan permasalahan sesuai fakta yang baru saja berlangsung.

Pengambilan responden secara Snowball sampling yakni menelusuri keberadaan responden dengan menanyakan beberapa orang yang dianggap sebagai informan kunci di lokasi penelitian. Penelitian ini dilakukan di kecamatan Lenangguar dan Moyo Utara kabupaten Sumbawa yang dilaksanakan dari februari hingga maret 2016. Kemudian pengumpulan data dilakukan dengan teknik pengamatan, kuisioner, wawancara dan dokumentasi.

\section{Analisis Data}

Analisis dalam penelitian strategi pengembangan usaha susu kuda Sumbawa digunakan dalam beberapa cara, yaitu analisis matriks Internal Factor Evaluation (IFE) dan External Factor Evaluation (EFE), analisis Strengths, Weaknesses, Opportunities dan Threats (SWOT), dan Quantitative Strategic Planning Matrix (QSPM) (Umar, 2008).

\section{HASIL DAN PEMBAHASAN}

Tahap Pengumpulan Data

\section{Matrix Internal Factor Evaluation (IFE)}

Kekuatan utama yang ditandai dengan nilai skor terbesar 0,399 yaitu pada harga 
produk lebih murah sedangkan kelemahan utama yang ditandai dengan nilai skor terbesar 0,234 yaitu belum memiliki label BPOM (lihat Tabel 1 matrix IFE).

Harga jual produk SKS yang dihasilkan di kecamatan Lenangguar dan Moyo Utara adalah Rp 40.000,-/btl (500ml), sedangkan produk kompetitor memiliki harga bervariatif diatas $\mathrm{Rp}$
80.000 ,-/btl (500ml). Hal ini dipengaruhi oleh pendeknya jalur distribusi sehingga dalam pembiayaan transport bahan baku sangat rendah.

Tabel 1. Matrik IFE

\begin{tabular}{|c|l|c|c|c|}
\hline \multicolumn{2}{|c|}{ Faktor Internal } & Bobot & Ranking & Skor \\
\hline \multirow{5}{*}{ Kekuatan } & Ketersediaan bahan baku (SKS) & 0,107 & 3,2 & 0,342 \\
\cline { 2 - 5 } & Kepemilikan usaha penuh & 0,071 & 3 & 0,213 \\
\cline { 2 - 5 } & Produk SKS asli dari Sumbawa & 0,096 & 3,2 & 0,307 \\
\cline { 2 - 5 } & Harga produk lebih murah & 0,121 & 3,3 & $\mathbf{0 , 3 9 9}$ \\
\cline { 2 - 5 } & Usaha yang menguntungkan & 0,094 & 3,1 & 0,291 \\
\hline \multirow{3}{*}{ Kelemahan } & & & 1,552 \\
\cline { 2 - 5 } & Subtotal & 0,13 & 1,8 & $\mathbf{0 , 2 3 4}$ \\
\cline { 2 - 5 } & Belum memiliki label BPOM & 0,125 & 1,7 & 0,212 \\
\cline { 2 - 5 } & Kemasan kurang menarik & 0,074 & 2 & 0,148 \\
\cline { 2 - 5 } & Rasa susu kuda asam dan khas & 0,085 & 1,7 & 0,145 \\
\cline { 2 - 5 } & Keterbatasan Modal & 0,096 & 1,9 & 0,182 \\
\hline \multicolumn{2}{|}{ Subtotal } & 1 & & 0.921 \\
\hline \multicolumn{2}{|c|}{ Total } & & 2,473 \\
\hline
\end{tabular}

Faktor harga produk selalu menjadi menjadi faktor penting dalam proses konteks setiap pembelian pelanggan/konsumen. Konsumen selalu memeriksa informasi harga dan nama merek berbeda ketika mereka akan memberikan penilaian pada produk (Rajput et al., 2012).

Namun, para responden juga menyadari bahwa keberadaan label BPOM diyakini sangat penting dalam mengembangkan usaha susu kuda Sumbawa.

\section{Matrix External Evaluation (EFE)}

Peluang utama yang ditandai dengan nilai skor terbesar yaitu gaya hidup sehat dan alami
Pengurusan berbelit-belit dan mahal menjadi alasan bagi pelaku usaha susu kuda Sumbawa tidak mengurus izin BPOM. Menurut mereka pula tidak adanya label BPOM ini ternyata tidak mengurangi permintaan yang selama ini diterima.

serta manfaat dan khasiat SKS sudah dikenal masyarakat yang ditandai dengan skor sama yakni 0,344 . Sementara ancaman utama yaitu tingkat inflasi dengan skor mencapai 0,272. (lihat Tabel 2. Matriks EFE).

Tabel 2. Matriks EFE

\begin{tabular}{|c|l|c|c|c|}
\hline \multicolumn{1}{|c|}{ Faktor Eksternal } & Bobot & Ranking & Skor \\
\hline Peluang & Trend hidup sehat dan alami & 0,111 & 3,1 & $\mathbf{0 , 3 4 4}$ \\
\cline { 2 - 4 } & $\begin{array}{l}\text { Penderita penyakit kronis masih } \\
\text { tinggi }\end{array}$ & 0,096 & 3 & 0,288 \\
\cline { 2 - 4 } & $\begin{array}{l}\text { Dukungan pemerintah terhadap } \\
\text { UMKM }\end{array}$ & 0,109 & 3,1 & 0,338 \\
\cline { 2 - 5 } & $\begin{array}{l}\text { Manfaat dan khasiat SKS sudah } \\
\text { dikenal masyarakat }\end{array}$ & 0,111 & 3,1 & $\mathbf{0 , 3 4 4}$ \\
\cline { 2 - 5 } & Produk eksklusif & 0,108 & 3,1 & 0,335 \\
\hline \multicolumn{1}{|c|}{ Subtotal } & & & 1,649 \\
\hline \multirow{2}{*}{ Ancaman } & Munculnya produk substitusi & 0,113 & 1,9 & 0,215 \\
\cline { 2 - 5 } & Inovasi produk kompetitor & 0,077 & 2,1 & 0,162 \\
\cline { 2 - 5 } & Munculnya produk SKS palsu & 0,077 & 2,7 & 0,208 \\
\cline { 2 - 5 } & $\begin{array}{l}\text { Munculnya pesaing yang juga menjual } \\
\text { susu kuda }\end{array}$ & 0,075 & 2,8 & 0,21 \\
\cline { 2 - 5 } & Tingkat inflasi & 0,136 & 2 & $\mathbf{0 , 2 7 2}$ \\
\hline \multicolumn{2}{|c|}{ Total } & 1 & & 2,067 \\
\hline
\end{tabular}


Slogan "back to nature" hadir dan menjadi trend dalam masyarakat. Trend tersebut terus meningkat seiring dengan meningkatnya pengetahuan masyarakat mengenai bahaya bahan-

bahan kimia dan sintetis, serta kelebihankelebihan dari produk-produk herbal. Peluang utama lainnya adalah Susu kuda Sumbawa telah dikenal oleh masyarakat sebagai obat berbagai jenis penyakit kronis seperti TBC, asam urat, darah tinggi, kanker,asma, dan sebagainya (Siwang, 2009).

Laju Inflasi dan indeks harga konsumen menunjukkan kenaikan harga barang-barang secara umum. Hal ini akan berakibat pada menurunnya daya beli konsumen sehingga akan menjadi ancaman terhadap permintaan produk susu kuda Sumbawa.

\section{Tahap Pencocokan (The Matching Stage)}

Input yang digunakan dalam matrix IE adalah total nilai skor dari matrix IFE dan matrix EFE. Total nilai skor matrix IFE diletakkan di sumbu vertikal dan total skor EFE diletakkan di sumbu horizontal. Total nilai skor IFE sebesar 2,473 dan total nilai skor EFE sebesar 2,716. Titik pertemuan dari kedua sumbu tersebut berada pada sel ke-V. artinya usaha susu kuda Sumbawa di kabupaten sumbawa mengalami pertumbuhan melalui integrasi horizontal dengan cara memperluas pasar, fasilitas produksi dan teknologi pengembangan internal maupun eksternal.

\section{Matrix SWOT}

Tabel 3. Matriks SWOT

\begin{tabular}{|c|c|c|}
\hline Faktor Internal & $\begin{array}{l}\text { Kekuatan (Strenghts) } \\
\text { 1. Ketersediaan bahan baku } \\
\text { (SKS) } \\
\text { 2. Kepemilikan usaha penuh } \\
\text { 3. Produk SKS asli dari } \\
\text { Sumbawa } \\
\text { 4. Harga produk lebih murah } \\
\text { 5. Usaha yang } \\
\text { menguntungkan }\end{array}$ & $\begin{array}{l}\text { Kelemahan (Weakness) } \\
\text { 1. Belum memiliki BPOM } \\
\text { 2. Tidak ada } \\
\text { pemasaran } \\
\text { 3. Kemasan kurang menarik } \\
\text { 4. Rasa susu kuda asam dan } \\
\text { khas } \\
\text { 5. Keterbatasan modal }\end{array}$ \\
\hline & & \\
\hline
\end{tabular}

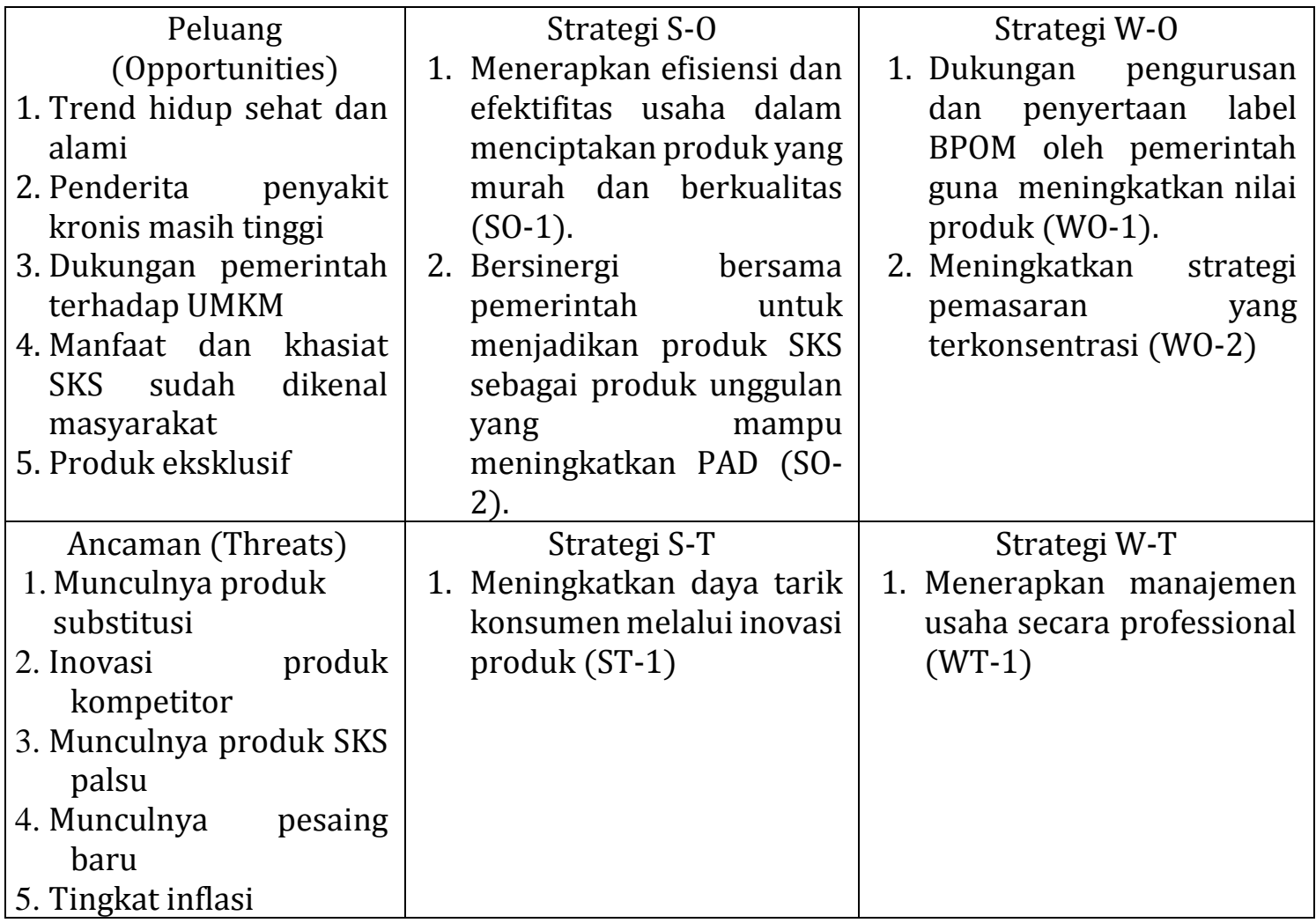




\section{(The Decision Stage)}

Matriks QSPM bertujuan untuk mengetahui strategi prioritas yang bisa diaplikasikan oleh usaha susu kuda Sumbawa. Matriks QSPM menggunakan nilai bobot dan

Tabel Nilai Total Atractive Score (TAS) Matrix Quantitative Strategic Planning Matrix (QSPM) nilai Attractive Score (AS) yang dinilai oleh responden secara objektif dan rasional. Kedua nilai tersebut akan didapatkan nilai Total Attractive Score (TAS).

\begin{tabular}{|c|c|c|c|c|c|c|}
\hline Nilai SWOT & ST 1 & ST 2 & ST 3 & ST 4 & ST 5 & ST 6 \\
\hline \multirow{5}{*}{$\begin{array}{l}\text { Kekuatan } \\
\text { (Strength) }\end{array}$} & 0,428 & 0,321 & 0,321 & 0,321 & 0,321 & 0,321 \\
\hline & 0,142 & 0,142 & 0,142 & 0,213 & 0,142 & 0,142 \\
\hline & 0,288 & 0,384 & 0,288 & 0,288 & 0,288 & 0,192 \\
\hline & 0,484 & 0,363 & 0,363 & 0,363 & 0,363 & 0,363 \\
\hline & 0,282 & 0,188 & 0,282 & 0,282 & 0,282 & 0,376 \\
\hline \multirow{5}{*}{$\begin{array}{c}\text { Kelemahan } \\
\text { (Weakness) }\end{array}$} & 0,39 & 0,52 & 0,52 & 0,39 & 0,39 & 0,39 \\
\hline & 0,375 & 0,375 & 0,375 & 0,5 & 0,375 & 0,375 \\
\hline & 0,148 & 0,222 & 0,222 & 0,296 & 0,222 & 0,222 \\
\hline & 0,255 & 0,255 & 0,255 & 0,34 & 0,34 & 0,255 \\
\hline & 0,288 & 0,288 & 0,384 & 0,288 & 0,384 & 0,288 \\
\hline \multirow{5}{*}{$\begin{array}{c}\text { Peluang } \\
\text { (Opportunitie } \\
s)\end{array}$} & 0,222 & 0,333 & 0,333 & 0,333 & 0,333 & 0,222 \\
\hline & 0,192 & 0,288 & 0,288 & 0,288 & 0,288 & 0,192 \\
\hline & 0,218 & 0,436 & 0,436 & 0,327 & 0,327 & 0,327 \\
\hline & 0,222 & 0,333 & 0,333 & 0,333 & 0,333 & 0,222 \\
\hline & 0,216 & 0,324 & 0,324 & 0,324 & 0,324 & 0,216 \\
\hline \multirow{5}{*}{$\begin{array}{l}\text { Ancaman } \\
\text { (Threats) }\end{array}$} & 0,339 & 0,226 & 0,339 & 0,339 & 0,339 & 0,339 \\
\hline & 0,231 & 0,154 & 0,231 & 0,231 & 0,308 & 0,231 \\
\hline & 0,154 & 0,231 & 0,231 & 0,231 & 0,231 & 0,231 \\
\hline & 0,15 & 0,15 & 0,225 & 0,225 & 0,225 & 0,225 \\
\hline & 0,272 & 0,408 & 0,408 & 0,408 & 0,408 & 0,408 \\
\hline Jumlah Total & $5,296^{(6)}$ & $5,941^{(4)}$ & $6,3^{(2)}$ & $6,32^{(1)}$ & $6,223^{(3)}$ & $5,537^{(5)}$ \\
\hline
\end{tabular}

Keterangan :

Angka subscribe(1-7) menunjukkan peringkat tertinggi hingga terendah berdasarkan besarnya jumlah total (TAS) setiap strateginya.

ST 1: Strategi 1 = Menerapkan efisiensi dan efektifitas usaha dalam menciptakan produk yang murah dan berkualitas

ST 2:Strategi $2=$ Bersinergi bersama pemerintah untuk menjadikan produk SKS sebagai produk unggulan yang mampu meningkatkan PAD

ST 3: Strategi $3=$ Dukungan pengurusan dan penyertaan label BPOM oleh pemerinath guna meningkatkan nilai produk.

ST 4: Strategi 4

ST 5: Strategi 5

ST 6: Straregi 6

Prioritas strategi pengembangan usaha susu kuda Sumbawa di kecamatan Lenangguar dan Moyo Utara berdasarkan hasil perhitungan QSPM yang didapat dari TAS tertinggi. Prioritas pertama adalah ST 4 yaitu meningkatkan strategi pemasaran secara terkonsentrasi. Prioritas kedua adalah ST 3 yaitu dukungan pengurusan dan penyertaan label BPOM oleh pemerintah guna meningkatkan nilai produk. Prioritas ketiga adalah ST 5 yaitu meningkatkan daya tarik konsumen melalui inovasi produk.

Prioritas keempat adalah ST 2 yakni bersinergi bersama pemerintah untuk menjadikan produk SKS sebagai produk unggulan yang mampu meningkatkan PAD. 
alami serta manfaat dan khasiat SKS sudah dikenal masyarakat, sedangkan ancaman utama yang ditandai dengan nilai skor terbesar yaitu tingkat inflasi.

Terdapat enam alternatif strategi yang dianjurkan. Prioritas strategi yang dipilih dan menjadi pilihan utama dalam pengembangan usaha SKS berdasarkan matriks QSPM adalah meningkatkan strategi pemasaran secara terkonsentrasi.

\section{DAFTAR PUSTAKA}

Dinas Peternakan Kabupaten Sumbawa. 2014. Laporan Tahunan Dinas Peternakan Kabupaten Sumbawa Tahun 2014.

Dinas Peternakan Kabupaten Sumbawa. Sumbawa Besar

Hermawati, D., M. Sudarwanto., S.T. Soekarto., F.R. Zakaria., S. Sudardjat dan F.S. Tjatur Rasa. 2004. Aktivitas Antimikroba Pada Susu Kuda sumbawa. Jurnal Teknologi dan Industri Pangan. 15 (1) : 47-53.

Rajput, A.A.; Kalhoro, S.H.; dan Wasif, R. 2012. Impact of Product Price and Quality on Consumer Buying Behavior: Evidence from Pakistan. Interdisciplinary Journal Of Contemporary Research In Business. ijcrb.webs.com. Vol 4, No 4. August, h.585-496.

Salimei, E., dan Fantuz, F. (2012). Equid milk for human consumption. International Dairy Journal, 24, 130-142.

Sheng, Q. dan X. Fang. 2009. Bioactive Component in mare milk. In : young. W.P. (Ed). Bioactive Component in Milk and Dairy Products. $1^{\text {st }}$ ed. Wiley Nlackwell, USA

Siwang, R. S. 2009. Analisis Strategi Pemasaran Produk Susu Kuda Organik "Asam Bugar" UKM Diana Hermawati Parung Bogor. Institur Pertanian Bogor (IPB). Bogor.

Umar, H. 2008. Management Strategy in Action. PT. Gramedia Pustaka Utama, Jakarta. 
